\title{
Preoperative C-Reactive Protein in the Serum: A Prognostic Biomarker for Upper Urinary Tract Urothelial Carcinoma Treated with Radical Nephroureterectomy
}

\author{
Atiqullah Aziz $^{\mathrm{a}, \mathrm{b}}$ Michael Rink ${ }^{\mathrm{b}}$ Georgios Gakis ${ }^{\mathrm{c}}$ Luis A. Kluth ${ }^{\mathrm{b}}$ \\ Christopher Dechet $^{d}$ Florian Miller $^{c}$ Wolfgang Otto ${ }^{a}$ Michael Gierth ${ }^{a}$ \\ Stefan Denzinger ${ }^{a}$ Christian Schwentner $^{c}$ Arnulf Stenzl $^{c}$ Margit Fisch $^{b}$ \\ Maximilian Burger ${ }^{a}$ Hans-Martin Fritsche ${ }^{a}$ \\ ${ }^{a}$ Department of Urology, Caritas St. Josef Medical Center, University of Regensburg, Regensburg, \\ ${ }^{b}$ Department of Urology, University Medical Center Hamburg-Eppendorf, Hamburg, and ${ }^{\mathrm{C}}$ Department of \\ Urology, Eberhard Karls University, Tübingen, Germany; ${ }^{\text {d} H u n t s m a n ~ C a n c e r ~ I n s t i t u t e, ~ D i v i s i o n ~ o f ~ U r o l o g y, ~}$ \\ University of Utah, Salt Lake City, Utah, USA
}

\section{Key Words}

C-reactive protein - Upper tract urothelial carcinoma ·

Nephroureterectomy · Prognosis · Survival

\begin{abstract}
Objective: To investigate the impact of preoperative serum C-reactive protein (CRP) on clinicopathological features and prognosis in patients with upper tract urothelial cancer (UTUC) after radical nephroureterectomy (RNU). Patients and Methods: Data of 265 patients from three German centers who underwent RNU for UTUC without neoadjuvant chemotherapy between 1990 and 2012 were evaluated. Mean follow-up was 37 months (interquartile range 9-48). CRP was analyzed as a categorical and continuous variable for the prediction of recurrence-free survival (RFS), diseasespecific survival (DSS) and all-cause survival (ACS) using uniand multivariate Cox regression analyses. Results: The optimal cutoff for CRP was calculated by the Youden index at $0.90 \mathrm{mg} / \mathrm{dl}$. Elevated CRP was significantly associated with
\end{abstract}

\section{KARGER}

E-Mail karger@karger.com

www.karger.com/uin
pT3/4 and pN+ in a preoperative model including age, gender, tumor multifocality, tumor localization and the Eastern Cooperative Oncology Group Performance Status. In a multivariable Cox regression model adjusted for features significant in univariable analysis, categorized and continuous CRP levels were both independent predictors for RFS [hazard ratio (HR) 1.18, $p=0.050 ; \mathrm{HR} 1.03, \mathrm{p}=0.012$ ] and DSS (HR $1.61, p=0.026 ; H R$ 1.06, $p=0.001)$. Continuous CRP was an independent predictor for ACS (HR 1.05, p = 0.036). Conclusions: Elevated preoperative CRP is significantly associated with aggressive tumor biology and an independent predictor for poor survival after RNU. Preoperative serum CRP represents an easily obtainable and cost-effective marker in UTUC and may help in counseling patients with regard to operative management and/or adjuvant or neoadjuvant therapies.

(c) 2014 S. Karger AG, Basel

\section{A. Aziz and M. Rink contributed equally to this work.}

Hans-Martin Fritsche, MD, FEBU

Department of Urology, Caritas St. Josef Medical Center, University of Regensburg Landshuter Strasse 65

DE-93053 Regensburg (Germany)

E-Mail hans-martin.fritsche@ukr.de 


\section{Introduction}

Upper tract urothelial carcinoma (UTUC) accounts for $5 \%$ of all urothelial cancers [1] and thus represents an uncommon and rare malignancy [2]. Radical nephroureterectomy (RNU) with bladder cuff excision remains the gold standard for treatment of UTUC [3]. Unfortunately, approximately $60 \%$ of UTUCs are diagnosed at an advanced tumor stage, resulting in a poor overall prognosis [3].

Several predictors of outcomes of UTUC have been investigated [4-8]. However, data using serum biomarkers are limited. The biomarker C-reactive protein (CRP) is an easily obtainable serum laboratory marker for inflammation used commonly in clinical practice. Indeed, elevation of CRP has already been shown to predict outcomes in renal cell, bladder and prostate cancer $[9,10]$. In UTUC, elevated preoperative serum CRP (sCRP) has been found to be an independent predictor of outcome following RNU [11-14].

The aim of this retrospective multi-institutional study was therefore threefold. First, we sought to evaluate the association between clinico-pathological features and preoperative sCRP. Second, the impact of preoperative sCRP on predicting advanced tumor stage (pT3/T4 or positive lymph nodes) was assessed. Third, we evaluated the ability of sCRP to predict recurrence and survival in patients with UTUC following RNU.

\section{Patients and Methods}

\section{Patient Selection and Data Collection}

This retrospective study involved three German academic centers (Hamburg, Tübingen and Regensburg). All centers agreed to transfer data into a common computerized database. Prior to study initiation, appropriate data-sharing agreements and institutional review board approval were obtained from each participating center. Data from a total of 348 patients from 1990 to 2012 with a history of UTUC treated with RNU without evidence of distant metastases were included in the study. Patients with a history of radical cystectomy for the treatment of muscle-invasive or high-risk non-muscle-invasive bladder cancer $(\mathrm{n}=11)$, with missing clinical data or follow-up $(n=42)$, with missing preoperative sCRP $(n=29)$ or treated with neoadjuvant chemotherapy $(\mathrm{n}=1)$ were excluded from the study. A total of 265 patients who underwent RNU for UTUC had complete datasets and formed the study cohort.

Prior to RNU, diagnostic ureterorenoscopy (6\%), ureterorenoscopy with biopsy $(56 \%)$ or imaging with selective upper urinary tract cytology (38\%) was performed. RNU was performed as described previously $[15,16]$. The kidney, entire ureteral length and adjacent segment of the bladder cuff were removed. Lymphadenectomy (hilar, regional) was performed in patients with suspicious lymph nodes on preoperative CT findings or with suspicious intraoperative findings and was performed at the discretion of the attending physician. The synchronous presence of two or more pathologically confirmed tumors in any location (renal pelvicalyceal system, ureter or both) was defined as tumor multifocality [17]. No patient received preoperative systemic chemotherapy or perioperative radiotherapy. Adjuvant chemotherapy was administered in 47 patients $(16.7 \%)$ at the treating physician's discretion. Systemic chemotherapy was platinum-based in $89 \%$ of the cases.

Preoperative measurement of sCRP was routinely performed up to 3 days prior to RNU. All patients were preoperatively screened for urinary tract infections using a dipstick test and/or urinary cultures. No patient with an active infection and/or fever $\left(>38.0^{\circ} \mathrm{C}\right)$ was included in the study. No patient had accompanying hematologic disorders, chronic inflammatory or autoimmune diseases, or had received prior steroid therapy. Due to the relatively short half-life of sCRP (approximately $24 \mathrm{~h}$ ) it seems unlikely that preoperative manipulations would have affected sCRP at the time of RNU.

\section{Pathologic Evaluation}

All surgical specimens were processed according to standard pathologic procedures and analyzed by experienced genitourinary pathologists at their respective centers. Pure variant histology was not observed in any patient [16]. All tumors were staged according to the 2010 American Joint Committee on Cancer TNM classification [18]. Tumor grading was performed according to the 1998 World Health Organization/International Society of Urological Pathology consensus classification [19]. Histopathologic evaluation included concomitant carcinoma in situ, tumor architecture (papillary or sessile according to the predominant feature of the index lesion [20]) and lymphovascular invasion (LVI; defined as the presence of tumor cells within an endothelium-lined space without underlying muscular walls [21]).

\section{Follow-Up}

Follow-up was performed according to protocols established at each respective center but followed current guideline recommendations [1]. In general, patients were followed every $3-4$ months for the first 2 years after RNU, every 6 months in years 3-5 and annually thereafter. Follow-up included a history and physical examination, urinary cytology and cystoscopic evaluation of the urinary bladder. CT of the abdomen including evaluation of the contralateral upper urinary tract and chest radiography were performed every 6 months or when clinically indicated. Bone or brain scans, thorax CT scans or magnetic resonance imaging were performed only when clinically indicated. Tumor relapse in the operative field, regional lymph nodes and/or distant metastasis was defined as disease recurrence. Urothelial carcinoma in the bladder or contralateral upper tract were viewed as metachronous tumors and not documented as a recurrence. Cause of death was determined by the treating physician, by chart review collaborated by death certificates or by death certificates alone [22]. To diminish bias in assigning the cause of death, all patients with UTUC listed on their death certificate and with documented previous disease progression were listed as having died of their UTUC. Perioperative mortality (i.e. any death within 30 days of surgery or before discharge) was not included for cancer-specific survival analyses. Duration of followup was assessed from the date of surgery until the last follow-up. Recurrence-free survival (RFS), disease-specific survival (DSS) and all-cause survival (ACS) were the end points of the study. 
Table 1. Clinicopathological characteristics of 265 UTUC patients treated with RNU according to sCRP levels

\begin{tabular}{|c|c|c|c|}
\hline \multirow[t]{2}{*}{ Variable } & \multicolumn{2}{|l|}{ CRP } & \multirow[t]{2}{*}{$\mathrm{p}$} \\
\hline & $\leq 0.90 \mathrm{mg} / \mathrm{dl}$ & $>0.90 \mathrm{mg} / \mathrm{dl}$ & \\
\hline Number & $116(56.2)$ & $149(44.8)$ & \\
\hline $\begin{array}{l}\text { Age at time of RNU } \\
\quad(\text { mean } \pm S D), \text { years }\end{array}$ & $67.7 \pm 9.85$ & $69.8 \pm 8.85$ & 0.060 \\
\hline Gender & & & 0.550 \\
\hline Male & $74(63.8)$ & $95(63.8)$ & \\
\hline Female & $42(36.2)$ & $54(36.2)$ & \\
\hline ECOG-PS & & & 0.442 \\
\hline 0 & $53(21.6)$ & $66(26.9)$ & \\
\hline$\geq 1$ & $50(20.4)$ & $76(31.0)$ & \\
\hline Tumor localization & & & 0.210 \\
\hline Pelvicalyceal & $57(39.3)$ & $88(60.7)$ & \\
\hline Ureter & $33(46.5)$ & $38(53.5)$ & \\
\hline Both & $26(53.1)$ & $23(46.9)$ & \\
\hline Tumor multifocality & & & 0.103 \\
\hline Single tumor & $69(59.9)$ & $105(70.5)$ & \\
\hline$\geq 2$ tumors & $47(40.5)$ & $44(29.5)$ & \\
\hline Pathologic tumor stage & & & $<0.001$ \\
\hline $\mathrm{Ta}-\mathrm{T} 1$ & $60(51.7)$ & $46(30.9)$ & \\
\hline $\mathrm{T} 2$ & $26(22.4)$ & $23(15.4)$ & \\
\hline T3 & $26(22.4)$ & $76(51.0)$ & \\
\hline $\mathrm{T} 4$ & $4(3.4)$ & $4(2.7)$ & \\
\hline $\begin{array}{l}\text { Advanced tumor stage } \\
\text { pT3/T4 }\end{array}$ & $30(25.9)$ & $80(53.7)$ & $<0.001$ \\
\hline Tumor grade & & & $<0.001$ \\
\hline 1 & $12(10.3)$ & $31(20.8)$ & \\
\hline 2 & $41(35.3)$ & $19(12.8)$ & \\
\hline 3 & $63(54.3)$ & $99(66.4)$ & \\
\hline Lymph node involvement & & & $<0.001$ \\
\hline $\begin{array}{l}\mathrm{pNX} \text { or } \mathrm{pN} 0 \\
\mathrm{pN}+\end{array}$ & $\begin{array}{r}102(87.9) \\
14(12.1)\end{array}$ & $\begin{array}{r}104(69.8) \\
45(30.2)\end{array}$ & \\
\hline$L V I$ & & & 0.002 \\
\hline Present & $13(11.5)$ & $39(26.4)$ & \\
\hline Absent & $100(88.5)$ & $109(73.6)$ & \\
\hline Tumor architecture & & & $<0.001$ \\
\hline Papillary & $100(86.2)$ & $98(65.8)$ & \\
\hline Sessile & $16(13.8)$ & $51(34.2)$ & \\
\hline Adjuvant chemotherapy & & & 0.190 \\
\hline Administered & $17(14.7)$ & $29(19.5)$ & \\
\hline Not administered & $99(85.3)$ & $120(80.5)$ & \\
\hline
\end{tabular}

Values represent numbers of patients with percentages in parentheses, except where indicated otherwise.
Statistical Analysis

The Youden index was applied to identify the optimal cutoff for preoperative sCRP levels. The Kolmogorov-Smirnov test was applied to investigate the normal distribution of continuous variables. Continuous variables are presented as means with standard deviations or medians with interquartile ranges depending on the type of distribution. The Wilcoxon rank sum test (Mann-Whitney $\mathrm{U}$ test for two categories) and the Kruskal-Wallis test (three or more categories) were applied for nonnormally distributed variables. Comparison between categorical variables was performed using Fisher's exact test and the $\chi^{2}$ test.

The impact of the preoperative features sCRP, age, gender, tumor multifocality, tumor localization and the Eastern Cooperative Oncology Group Performance Status (ECOG-PS) on predicting advanced-stage disease (pT3/T4 or N1 disease) was analyzed using a binary logistic regression analysis.

RFS, DSS and ACS rates were estimated using the Kaplan-Meier method; the log-rank test was employed to compare survival curves. Cox proportional hazards regression models were performed to assess the influence of clinicopathological parameters on disease recurrence and mortality. The impact of categorized and continuous preoperative sCRP in multivariable models was assessed using the area under the curve (AUC) of the receiver operator characteristic. Evaluation of AUC values (c-indices) for estimation of the predictive accuracy (PA) was performed according to Harrell et al. [23]. The c-indices were compared with the Mantel-Haenszel test.

Statistical analyses were performed with SPSS Statistics ${ }^{\circledR} 20$ (SPSS, IBM Corp., Armonk, N.Y., USA) and R (version 3.0.0, The R Foundation for Statistical Computing, Vienna, Austria). Reported $\mathrm{p}$ values are two-sided with the statistical significance level set at $\mathrm{p} \leq 0.05$.

\section{Results}

The descriptive characteristics of the study population are displayed in table 1 . The optimal cutoff for the preoperative sCRP level was defined by the Youden index as $0.90 \mathrm{mg} / \mathrm{dl}$. sCRP levels $>0.90 \mathrm{mg} / \mathrm{dl}$ were classified as being elevated. Our study group comprised a total of 149 patients $(44.8 \%)$ with sCRP levels $>0.90 \mathrm{mg} / \mathrm{dl}$ and 116 patients (56.2\%) with sCRP levels $\leq 0.90 \mathrm{mg} / \mathrm{dl}$. The mean age in the two groups was 69.8 and 67.7 years $(p=0.060)$, respectively. Distribution of gender was equal in both groups $(\mathrm{p}=0.550)$. Patients with sCRP levels $>0.90 \mathrm{mg} /$ $\mathrm{dl}$ presented more commonly with advanced $\mathrm{pT}$ stages pT3/4 (53.7 vs. $25.9 \%$; p < 0.001), grade G3 tumors (66.4 vs. $54.3 \%$; $\mathrm{p}<0.001)$, lymph node involvement (30.2 vs. $12.1 \%$; $<0.001)$ and LVI (26.4 vs. $11.5 \%$; $=0.002$ ). Sessile tumors were more commonly observed in patients with sCRP levels $>0.90 \mathrm{mg} / \mathrm{dl}$ (34.2 vs. $13.8 \%$; $\mathrm{p}<0.001$ ). No further significant CRP level-specific differences were seen when comparing ECOG-PS, tumor multifocality, tumor localization and administration of adjuvant chemotherapy. 
Table 2. Preoperative binary logistic regression model predicting advanced tumor stage pT3/pT4 and positive lymph node involvement in 265 UTUC patients treated with RNU

\begin{tabular}{llc}
\hline Variable & HR $(95 \% \mathrm{CI})$ & $\mathrm{p}$ \\
\hline Prediction of advanced tumor stage pT3/pT4 & & \\
Age at RNU (continuous; years) & $1.02(0.98-1.05)$ & 0.381 \\
Female gender (reference: male) & $1.22(0.69-2.15)$ & 0.487 \\
ECOG-PS $\geq 1$ (reference: ECOG-PS 0) & $1.20(0.68-2.20)$ & 0.550 \\
Tumor multifocality ( $\geq 2$ tumors vs. single tumor) & $1.74(0.77-3.93)$ & 0.185 \\
Tumor localization & & \\
$\quad$ Ureteral vs. pelvicalyceal & $0.68(0.35-1.32)$ & 0.257 \\
$\quad$ Both vs. pelvicalyceal only & $0.47(0.17-1.30)$ & 0.146 \\
Serum CRP level >0.90 mg/dl (reference: $\leq 0.90 \mathrm{mg} / \mathrm{dl})$ & $3.79(2.11-6.80)$ & $<0.001$ \\
\hline Prediction of positive lymph node involvement & & 0.394 \\
Age at RNU (continuous; years) & $1.02(0.98-1.06)$ & 0.879 \\
Female gender (reference: male) & $0.95(0.50-1.82)$ & 0.481 \\
ECOG-PS $\geq 1$ (reference: ECOG-PS 0) & $1.28(0.64-2.59)$ & 0.332 \\
Tumor multifocality ( $\geq 2$ tumors vs. single tumor) & $1.55(0.64-3.78)$ & \\
Tumor localization & & \\
$\quad$ Ureteral vs. pelvicalyceal & $0.88(0.43-1.84)$ & 0.740 \\
$\quad$ Both vs. pelvicalyceal only & $0.34(0.10-1.14)$ & 0.080 \\
Serum CRP level >0.90 mg/dl (reference: $\leq 0.90 \mathrm{mg} / \mathrm{dl})$ & $2.65(1.32-5.30)$ & 0.006 \\
\hline
\end{tabular}

In a binary logistic regression model for the calculation of the predictive capacity of preoperative features for advanced disease, an elevated preoperative sCRP $>0.90$ $\mathrm{mg} / \mathrm{dl}$ was the only independent predictor for $\mathrm{pT} 3 / \mathrm{pT} 4$ [hazard ratio (HR) 3.79, $\mathrm{p}<0.001$ ] and $\mathrm{pN}+$ disease (HR 2.65, $\mathrm{p}=0.006)$ (table 2).

Mean follow-up was 37 months (interquartile range 10-48, median 23). During follow-up, disease recurred in 92 patients $(34.7 \%), 69$ patients $(26.0 \%)$ died of UTUC and the rate of all-cause mortality was $49.1 \%$ (130 patients). The 5 -year RFS rate was $44 \%$ in patients with CRP levels $\leq 0.90 \mathrm{mg} / \mathrm{dl}$ and $39 \%$ in patients with sCRP levels $>0.90 \mathrm{mg} / \mathrm{dl}$ ( $\mathrm{p}=0.062$; fig. $1 \mathrm{a})$. The 5 -year DSS rate was $68 \%$ in patients with CRP levels $\leq 0.90 \mathrm{mg} / \mathrm{dl}$ and $51 \%$ in patients with sCRP levels $>0.90 \mathrm{mg} / \mathrm{dl}$ ( $\mathrm{p}=0.005$; fig. $1 \mathrm{~b})$. The corresponding 5-year ACS rates were 25 and 13\%, respectively ( $\mathrm{p}=0.016$; fig. $1 \mathrm{c})$.

In univariable analysis (table 3 ), ECOG-PS $\geq 1$ (HR $1.66, \mathrm{p}=0.029)$, multifocality (HR 1.71, $\mathrm{p}=0.11$ ), tumor stage (HR 3.99, $\mathrm{p}<0.001$ ), tumor grade (HR 2.85, $\mathrm{p}<$ 0.001 ), lymph node involvement (HR 2.07, $\mathrm{p}=0.001$ ), LVI (HR 4.16, $\mathrm{p}<0.001$ ), tumor architecture (HR 1.87, $\mathrm{p}=0.005), \mathrm{sCRP}>0.90 \mathrm{mg} / \mathrm{dl}(\mathrm{HR} 1.49, \mathrm{p}=0.036)$ and continuous sCRP (HR 1.54, $\mathrm{p}=0.004$ ) were significantly associated with RFS. ECOG-PS $\geq 1$ (HR 2.17, $\mathrm{p}=0.005$ ), tumor stage (HR 5.38, p < 0.001), tumor grade (HR 3.24, $\mathrm{p}<0.001$ ), lymph node involvement (HR 2.74, $\mathrm{p}=0.001)$,

CRP as a Predictor for Survival after RNU for UTUC
LVI (HR 4.47, $\mathrm{p}<0.001)$, tumor architecture (HR 2.18, $\mathrm{p}=0.002), \mathrm{sCRP}>0.90 \mathrm{mg} / \mathrm{dl}(\mathrm{HR} 2.07, \mathrm{p}=0.006)$ and continuous sCRP (HR 1.08, $\mathrm{p}<0.001$ ) were significantly associated with DSS. Age (HR 1.03, p = 0.020), ECOG-PS $\geq 1$ (HR 1.55, $\mathrm{p}=0.022$ ), tumor stage (HR 2.83, $<<0.001$ ), tumor grade (HR 1.89, $\mathrm{p}=0.001$ ), lymph node involvement (HR 1.92, p = 0.001), LVI (HR 2.92, $\mathrm{p}<0.001)$, tumor architecture (HR 1.57, $\mathrm{p}=0.021$ ), sCRP $>0.90 \mathrm{mg} / \mathrm{dl}$ (HR 1.55, p = 0.017) and continuous sCRP (HR 1.06, $\mathrm{p}<$ $0.001)$ were significantly associated with ACS.

In multivariable Cox regression analysis that adjusted for significant parameters in univariable analysis (table 3), tumor stage (HR 2.61, p = 0.001), LVI (HR 2.70, $\mathrm{p}<0.001)$, sCRP $>0.90 \mathrm{mg} / \mathrm{dl}(\mathrm{HR} 1.18, \mathrm{p}=0.050)$ and continuous sCRP (HR 1.03, $p=0.012$ ) were independent predictors of disease recurrence. The respective $\mathrm{c}$-indices of this model with and without inclusion of dichotomized and continuous sCRP were 0.728 and 0.714 (PA gain $1.4 \%, \mathrm{p}=0.049)$ and 0.779 and 0.754 (PA gain $2.5 \%, \mathrm{p}=$ 0.039 ). Furthermore, tumor stage (HR 2.60, $\mathrm{p}=0.002$ ), LVI (HR 2.50, $\mathrm{p}<0.001$ ), sCRP >0.90 mg/dl (HR 1.61, $\mathrm{p}=0.026)$ and continuous sCRP (HR 1.06, $\mathrm{p}=0.001)$ independently impacted DSS. The respective c-indices of the DSS model with and without inclusion of dichotomized and continuous sCRP were 0.741 and 0.729 (PA gain $1.2 \%, \mathrm{p}=0.044)$ and 0.744 and $0.726(\mathrm{PA}$ gain $1.8 \%$, $\mathrm{p}=0.048)$. Age (HR 1.03, $\mathrm{p}=0.011)$, tumor stage $(\mathrm{HR}$ 


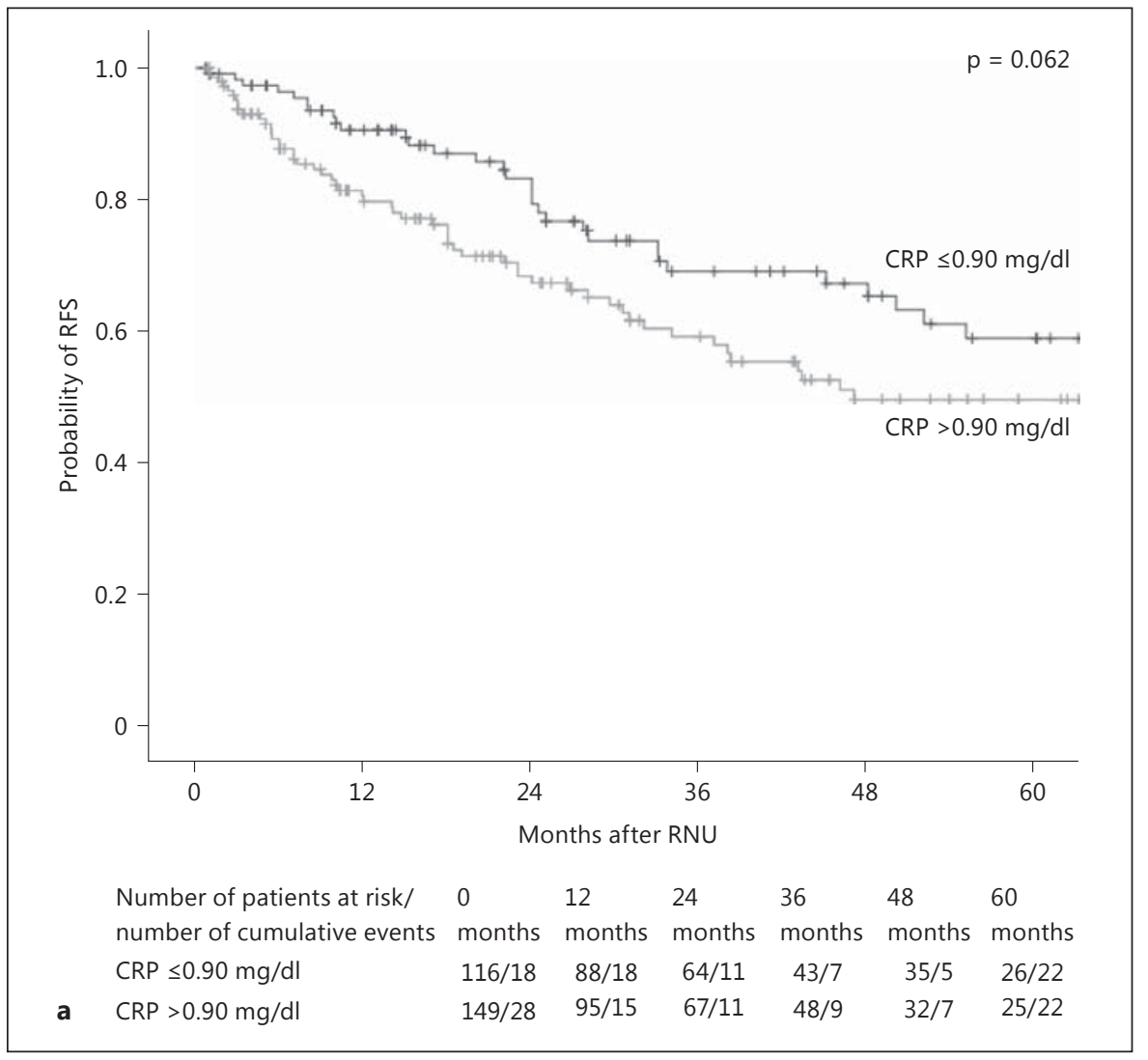

Fig. 1. Kaplan-Meier plots displaying probabilities of RFS (a), DSS (b) and ACS (c) according to preoperative sCRP levels in 265 UTUC patients treated with RNU.

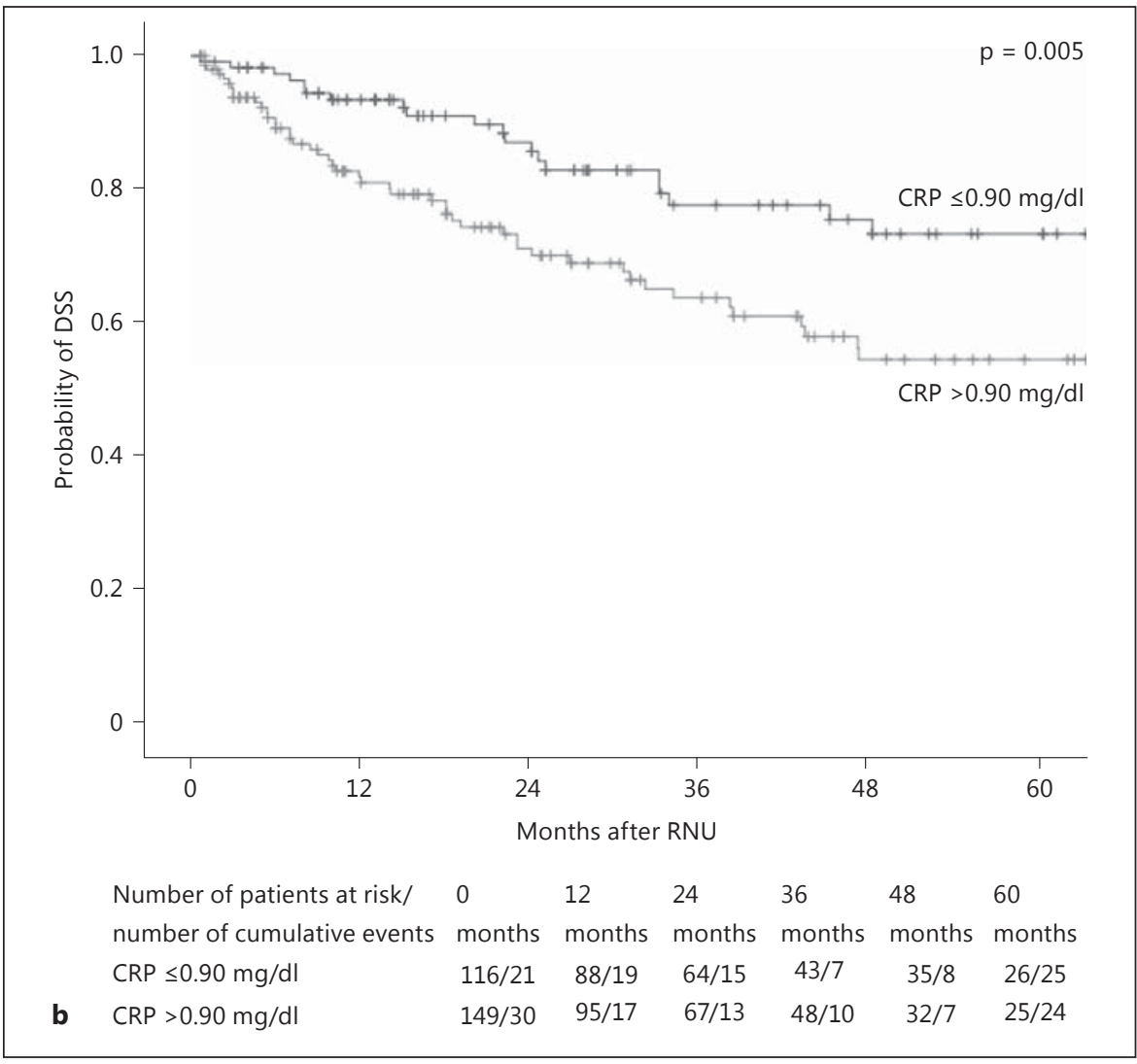

(For figure 1c see next page.) 


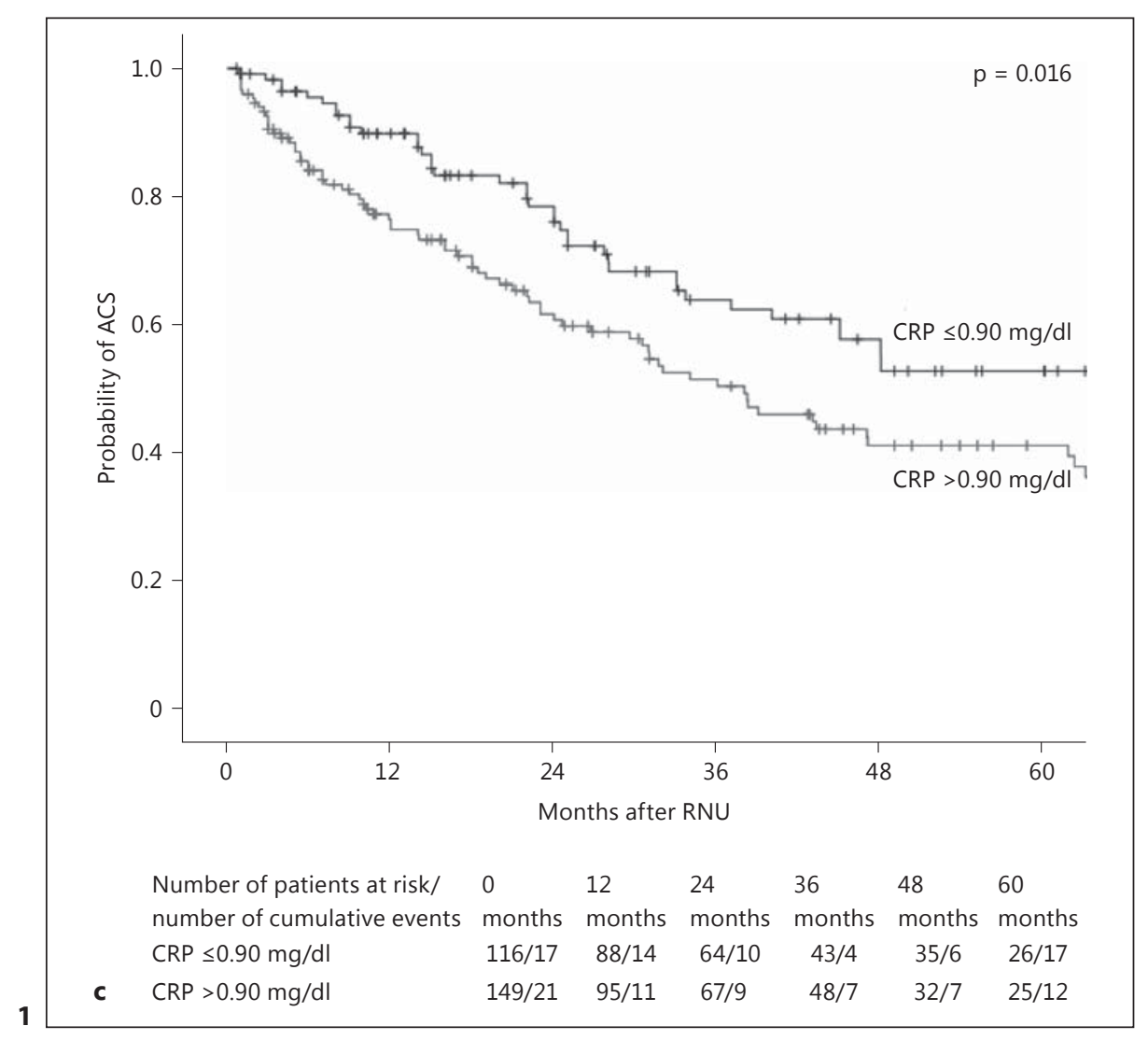

2.37, $\mathrm{p}<0.001)$, LVI (HR 1.91, $\mathrm{p}=0.004)$ and continuous sCRP (HR 1.05, $\mathrm{p}=0.036$ ) were significant predictors of ACS. The respective $c$-indices of this model with and without inclusion of continuous sCRP were 0.706 and 0.676 (PA gain $3.0 \%, \mathrm{p}=0.039$ ).

\section{Discussion}

The aim of the present study was to analyze the predictive impact of preoperative sCRP levels for patients with UTUC treated with RNU. Our findings confirm that preoperative sCRP levels have a significant association with aggressive tumor biology and poor outcome in UTUC. We found that CRP levels were a strong predictor for RFS, DSS and ACS, respectively.

We could not verify the results of a previous study [14] using a preoperative CRP threshold level of $0.50 \mathrm{mg} /$ $\mathrm{dl}$ as an independent predictor of DSS. These authors used this CRP cutoff based on the manufacturing recommendations that a value of $<0.50 \mathrm{mg} / \mathrm{ml}$ is considered normal [24]. In contrast, we sought to determine the op-

CRP as a Predictor for Survival after RNU for UTUC timal cutoff point for sCRP levels. Therefore, we investigated different preoperative sCRP cutoff values in order to determine the optimal predictor of RFS, DSS and ACS. Our calculations revealed a cutoff of $0.90 \mathrm{mg} / \mathrm{dl}$, as defined by the Youden index.

Saito et al. [11] published the first retrospective study addressing CRP in UTUC. In their single-center study with 130 UTUC patients, 24 patients (18\%) had elevated preoperative CRP levels of $>0.50 \mathrm{mg} / \mathrm{dl}$. Higher tumor stage and grade, positive lymph node involvement and the presence of LVI were significantly associated with elevated CRP levels. In line with our results, the authors identified elevated preoperative sCRP levels as an independent predictor of both RFS and DSS. However, the authors did not evaluate the association between sCRP and ACS. In the present study, continuous sCRP independently predicted ACS. Stein et al. [13] found that continuous sCRP was an independent prognosticator for DSS. The authors were able to demonstrate that a CRP value $>5 \mathrm{mg} / \mathrm{l}$ was significantly associated with DSS in univariable Cox regression analysis. Unfortunately, no data for categorized CRP values were shown in their mul- 
Table 3. Uni- and multivariable regression analysis predicting disease recurrence, disease-specific and all-cause mortality in 265 UTUC patients treated with RNU

\begin{tabular}{|c|c|c|c|c|}
\hline \multirow[t]{2}{*}{ Variable } & \multicolumn{2}{|c|}{ Univariable regression analysis } & \multicolumn{2}{|c|}{ Multivariable regression analysis } \\
\hline & $\operatorname{HR}(95 \% \mathrm{CI})$ & $\mathrm{p}$ value & HR (95\% CI) & $\mathrm{p}$ value \\
\hline \multicolumn{5}{|l|}{ Disease recurrence } \\
\hline Age at RNU (continuous; years) & $0.99(0.98-1.02)$ & 0.825 & - & - \\
\hline Female gender (ref.: male) & $1.81(0.77-1.80)$ & 0.441 & - & - \\
\hline ECOG-PS $\geq 1$ (ref.: ECOG-PS 0) & $1.66(1.05-2.62)$ & 0.029 & $1.29(0.79-2.11)$ & 0.301 \\
\hline Tumor multifocality ( $\geq 2$ tumors vs. single tumor) & $1.71(1.13-2.59)$ & 0.011 & $1.46(0.91-2.34)$ & 0.118 \\
\hline \multicolumn{5}{|l|}{ Tumor localization } \\
\hline Ureteral vs. pelvicalyceal & $0.81(0.50-1.33)$ & 0.412 & - & - \\
\hline Both vs. pelvicalyceal only & $0.72(0.39-1.34)$ & 0.297 & - & - \\
\hline pT3/4 (ref.: $\leq \mathrm{T} 2$ ) & $3.99(2.59-6.15)$ & $<0.001$ & $2.61(1.51-4.50)$ & 0.001 \\
\hline G3 (ref.: G1/G2) & $2.85(1.78-4.55)$ & $<0.001$ & $1.37(0.77-2.46)$ & 0.284 \\
\hline Lymph node involvement ( $\mathrm{pN}+\mathrm{vs} . \mathrm{pN} 0 / \mathrm{pNX})$ & $2.07(1.34-3.19)$ & 0.001 & $0.90(0.52-1.58)$ & 0.717 \\
\hline LVI (ref.: negative) & $4.16(2.70-6.41)$ & $<0.001$ & $2.70(1.59-4.57)$ & $<0.001$ \\
\hline Tumor architecture (sessile vs. papillary) & $1.87(1.21-2.91)$ & 0.005 & $1.03(0.59-1.81)$ & 0.923 \\
\hline \multicolumn{5}{|l|}{ Preoperative serum CRP level } \\
\hline$\leq 0.50$ vs. $>0.50 \mathrm{mg} / \mathrm{dl}$ & $1.20(0.75-1.91)$ & 0.451 & - & - \\
\hline$\leq 0.90$ vs. $>0.90 \mathrm{mg} / \mathrm{dl}$ & $1.49(0.98-2.27)$ & 0.036 & $1.18(0.71-1.97)$ & 0.050 \\
\hline Continuous & $1.54(1.02-1.09)$ & 0.004 & $1.03(0.98-1.08)$ & 0.012 \\
\hline \multicolumn{5}{|l|}{ Disease-specific mortality } \\
\hline Age at RNU (continuous; years) & $1.01(0.98-1.04)$ & 0.440 & - & - \\
\hline Female gender (ref.: male) & $1.10(0.65-1.73)$ & 0.820 & - & - \\
\hline ECOG-PS $\geq 1$ (ref.: ECOG-PS 0) & $2.17(1.26-3.74)$ & 0.005 & $1.74(0.96-3.14)$ & 0.066 \\
\hline Tumor multifocality ( $\geq 2$ tumors vs. single tumor) & $1.59(0.99-2.56)$ & 0.060 & $0.64(0.33-1.24)$ & 0.185 \\
\hline \multicolumn{5}{|l|}{ Tumor localization } \\
\hline Ureteral vs. pelvicalyceal & $0.80(0.46-1.41)$ & 0.448 & $0.70(0.36-1.37)$ & 0.303 \\
\hline Both vs. pelvicalyceal only & $0.80(0.40-1.59)$ & 0.521 & $0.77(0.30-2.01)$ & 0.595 \\
\hline pT3/4 (ref.: $\leq \mathrm{T} 2)$ & $5.38(2.75-10.5)$ & $<0.001$ & $2.60(1.44-4.68)$ & 0.002 \\
\hline G3 (ref.: G1/G2) & $3.24(1.84-5.68)$ & $<0.001$ & $1.57(0.84-2.98)$ & 0.160 \\
\hline Lymph node involvement ( $\mathrm{pN}+\mathrm{vs} . \mathrm{pN} 0 / \mathrm{pNX})$ & $2.74(1.69-4.43)$ & $<0.001$ & $1.29(0.74-2.70)$ & 0.371 \\
\hline LVI (ref.: negative) & $4.47(2.75-7.28)$ & $<0.001$ & $2.50(1.45-4.30)$ & $<0.001$ \\
\hline Tumor architecture (sessile vs. papillary) & $2.18(1.33-3.57)$ & 0.002 & $1.00(0.51-1.60)$ & 0.740 \\
\hline \multicolumn{5}{|l|}{ Preoperative serum CRP level } \\
\hline$\leq 0.50$ vs. $>0.50 \mathrm{mg} / \mathrm{dl}$ & $1.39(0.80-2.44)$ & 0.246 & - & - \\
\hline$\leq 0.90$ vs. $>0.90 \mathrm{mg} / \mathrm{dl}$ & $2.07(1.24-3.46)$ & 0.006 & $1.61(0.95-2.73)$ & 0.026 \\
\hline Continuous & $1.08(1.04-1.11)$ & $<0.001$ & $1.06(1.02-1.10)$ & 0.001 \\
\hline \multicolumn{5}{|l|}{ All-cause mortality } \\
\hline Age at RNU (continuous; years) & $1.03(1.01-1.05)$ & 0.020 & $1.03(1.01-1.05)$ & 0.011 \\
\hline Female gender (ref.: male) & $1.05(0.73-1.52)$ & 0.800 & - & - \\
\hline ECOG-PS $\geq 1$ (ref.: ECOG-PS 0) & $1.55(1.06-2.25)$ & 0.022 & $1.18(0.76-1.83)$ & 0.456 \\
\hline Tumor multifocality ( $\geq 2$ tumors vs. single tumor) & $1.27(0.88-1.82)$ & 0.200 & - & - \\
\hline \multicolumn{5}{|l|}{ Tumor localization } \\
\hline Ureteral vs. pelvicalyceal & $1.00(0.67-1.49)$ & 1.00 & - & - \\
\hline Both vs. pelvicalyceal only & $0.87(0.52-1.44)$ & 0.581 & - & - \\
\hline pT3/4 (ref.: $\leq \mathrm{T} 2)$ & $2.83(1.90-4.21)$ & $<0.001$ & $2.37(1.56-3.62)$ & $<0.001$ \\
\hline G3 (ref.: G1/G2) & $1.89(1.31-2.72)$ & 0.001 & $1.11(0.73-1.70)$ & 0.625 \\
\hline Lymph node involvement ( $\mathrm{pN}+\mathrm{vs} . \mathrm{pN} 0 / \mathrm{pNX})$ & $1.92(1.33-2.79)$ & 0.001 & $1.13(0.73-1.76)$ & 0.584 \\
\hline LVI (ref.: negative) & $2.92(1.97-4.33)$ & $<0.001$ & $1.91(1.22-2.98)$ & 0.004 \\
\hline Tumor architecture (sessile vs. papillary) & $1.57(1.07-2.31)$ & 0.021 & $0.87(0.55-1.36)$ & 0.531 \\
\hline \multicolumn{5}{|l|}{ Preoperative serum CRP level } \\
\hline$\leq 0.50$ vs. $>0.50 \mathrm{mg} / \mathrm{dl}$ & $1.37(0.91-2.06)$ & 0.130 & - & - \\
\hline$\leq 0.90$ vs. $>0.90 \mathrm{mg} / \mathrm{dl}$ & $1.55(1.08-2.21)$ & 0.017 & $1.23(0.84-1.80)$ & 0.280 \\
\hline Continuous & $1.06(1.02-1.01)$ & $<0.001$ & $1.05(1.02-1.09)$ & 0.036 \\
\hline
\end{tabular}

ref. = Reference; $\mathrm{pT}=$ pathological tumor stage; $\mathrm{G}=$ tumor grading; $\mathrm{pN}=$ pathological nodal stage. 
tivariable analysis. In our study, elevated sCRP levels categorized at $0.90 \mathrm{mg} / \mathrm{dl}$ independently influenced both RFS and DSS. Tanaka et al. [14] previously published a study subdividing patients into 3 groups according to preoperative sCRP values. The authors found that elevated preoperative sCRP levels significantly impacted on both RFS and DSS. Furthermore, they were able to demonstrate in a subgroup analysis that postoperative normalization of CRP levels was associated with improved outcomes [14]. In order to substantiate this finding, we also performed a subgroup analysis in our patients who showed an elevated preoperative sCRP level and postoperative normalization of the CRP levels $(n=143)$. However, we could not find any impact of sCRP on RFS, DSS and ACS in this scenario within the present study. In addition, the findings of our preoperative model for prediction of an advanced pathological tumor stage of pT3/pT4 and positive lymph node involvement revealed sCRP as an independent predictor for both of these end points. To the best of our knowledge, our findings are currently the first to address this issue.

Although several reports describe the independent association of elevated preoperative sCRP levels with poorer outcomes in various malignancies, the reasons for this finding remain unclear [25]. Three hypotheses have been postulated to date. First, elevated CRP levels may reflect a tumor's ability to produce large amounts of proinflammatory cytokines, notably interleukin-6, which may contribute to tumor growth $[26,27]$. Secondly, CRP might reflect an altered immune function, which consequently leads to tumor proliferation and dissemination [28, 29]. Third, proinflammatory cytokines are able to stimulate endothelial cells, fibroblasts and anti-inflammatory cells directly within the tumor, thereby enhancing angiogenesis, invasion, metastases and immune suppression [30, 31]. Influencing these pathways has been considered in novel therapeutic approaches [32]. Finally, elevated sCRP levels are associated with unintended weight loss and tissue destruction that might also contribute to a poorer DSS [33].

Although our study is one of the largest investigating the impact of sCRP levels on UTUC outcomes, we recognize some limitations of this retrospective study. We were unable to adjust for the possible influence of numerous surgeons at each institution with differing preferences, experience and techniques. The absence of a standard lymphadenectomy as well as differences in the lymph node counts may also bias our findings. We also cannot exclude differences between pathologists, as a central pathology review was not conducted. However, all surgeons and pathologists operated at centers experienced in the management of UTUC. Finally, sCRP levels may have been influenced by other underlying disease processes, which were not identified preoperatively. We were also unable to account for differences between the time of the initial CRP blood draw and subsequent RNU. Despite these limitations, this represents one of the largest multiinstitutional studies investigating the role of CRP in UTUC. However, our findings need to be verified in prospective, randomized studies.

\section{Conclusion}

In conclusion, preoperative elevation of the nonspecific inflammatory biomarker sCRP was significantly associated with adverse tumor biology and poor outcome after RNU. Our results confirm previous findings establishing this biomarker as a simple and cost-effective serum biomarker for the preoperative prediction of advanced tumor stage and poorer survival in UTUC. CRP may further help identify high-risk patients and guide operative management and decision-making with regard to neoadjuvant or adjuvant therapies.

\section{References}

1 Rouprêt M, Babjuk M, Compérat E, et al: European guidelines on upper tract urothelial carcinomas: 2013 update. Eur Urol 2013;63: 1059-1071.

-2 Siegel R, Naishadham D, Jemal A: Cancer statistics, 2012. CA Cancer J Clin 2012;62:10-29.

-3 Margulis V, Shariat SF, Matin SF, et al; Upper Tract Urothelial Carcinoma Collaboration: Outcomes of radical nephroureterectomy: a series from the Upper Tract Urothelial Carcinoma Collaboration. Cancer 2009;115:1224-1233.
4 Lughezzani G, Burger M, Margulis V, et al: Prognostic factors in upper urinary tract urothelial carcinomas: a comprehensive review of the current literature. Eur Urol 2012;62:100114.

5 Cho DS, Kim SI, Ahn HS, Kim SJ: Predictive factors for bladder recurrence after radical nephroureterectomy for upper urinary tract urothelial carcinoma. Urol Int 2013;91:153159.
6 Kuroda K, Asakuma J, Horiguchi A, et al Prognostic factors for upper urinary tract urothelial carcinoma after nephroureterectomy. Urol Int 2012;88:225-231.

7 Jang NY, Kim IA, Byun SS, Lee SE, Kim JS: Patterns of failure and prognostic factors for locoregional recurrence after radical surgery in upper urinary tract transitional cell carcinoma: implications for adjuvant radiotherapy. Urol Int 2013;90:202-206. 
8 Fang D, Li XS, Xiong GY, Yao L, He ZS, Zhou LQ: Prophylactic intravesical chemotherapy to prevent bladder tumors after nephroureterectomy for primary upper urinary tract urothelial carcinomas: a systematic review and meta-analysis. Urol Int 2013;91:291-296.

-9 Gakis G, Todenhöfer T, Renninger M, et al: Development of a new outcome prediction model in carcinoma invading the bladder based on preoperative serum C-reactive protein and standard pathological risk factors: the TNR-C score. BJU Int 2011;108:18001805.

10 Saito K, Kihara K: C-reactive protein as a biomarker for urological cancers. Nat Rev Urol 2011;8:659-666.

11 Saito K, Kawakami S, Ohtsuka Y, et al: The impact of preoperative serum C-reactive protein on the prognosis of patients with upper urinary tract urothelial carcinoma treated surgically. BJU Int 2007;100:269-273.

12 Obata J, Kikuchi E, Tanaka N, et al: C-reactive protein: a biomarker of survival in patients with localized upper tract urothelial carcinoma treated with radical nephroureterectomy. Urol Oncol 2013;31:1725-1730.

13 Stein B, Schrader AJ, Wegener G, et al: Preoperative serum $\mathrm{C}$-reactive protein: a prognostic marker in patients with upper urinary tract urothelial carcinoma. BMC Cancer 2013;13 101.

14 Tanaka N, Kikuchi E, Shirotake S, et al: The predictive value of C-reactive protein for prognosis in patients with upper tract urothelial carcinoma treated with radical nephroureterectomy: a multi-institutional study. Eur Urol 2014;65:227-234.

15 Rink M, Ehdaie B, Cha EK, et al: Stage-specific impact of tumor location on oncologic outcomes in patients with upper and lower tract urothelial carcinoma following radical surgery. Eur Urol 2012;62:677-684.
16 Rink M, Robinson BD, Green DA, et al: Impact of histological variants on clinical outcomes of patients with upper urinary tract urothelial carcinoma. J Urol 2012;188:398-404.

17 Chromecki TF, Cha EK, Fajkovic H, et al: The impact of tumor multifocality on outcomes in patients treated with radical nephroureterectomy. Eur Urol 2012;61:245-253.

18 Edge SB, Byrd DR, Compton CC, et al: American Joint Committee on Cancer (AJCC) Staging Manual. New York, Springer, 2010.

19 Epstein JI, Amin MB, Reuter VR, Mostofi FK: The World Health Organization/International Society of Urological Pathology consensus classification of urothelial (transitional cell) neoplasms of the urinary bladder. Bladder Consensus Conference Committee. Am J Surg Pathol 1998;22:1435-1448.

20 Remzi M, Haitel A, Margulis V, et al: Tumour architecture is an independent predictor of outcomes after nephroureterectomy: a multiinstitutional analysis of 1363 patients. BJU Int 2009;103:307-311.

21 Kikuchi E, Margulis V, Karakiewicz P, et al: Lymphovascular invasion predicts clinical outcomes in patients with node-negative upper tract urothelial carcinoma. J Clin Oncol 2009;27:612-618

22 Rink M, Fajkovic H, Cha EK, et al: Death certificates are valid for the determination of cause of death in patients with upper and lower tract urothelial carcinoma. Eur Urol 2012; 61:854-855.

23 Harrell FE Jr, Lee KL, Mark DB: Multivariable prognostic models: issues in developing models, evaluating assumptions and adequacy, and measuring and reducing errors. Stat Med 1996;15:361-387.
24 Komai Y, Saito K, Sakai K, Morimoto S: Increased preoperative serum $\mathrm{C}$-reactive protein level predicts a poor prognosis in patients with localized renal cell carcinoma. BJU Int 2006;99:77-80.

25 Gakis G, Todenhöfer T, Stenzl A: The prognostic value of hematological and systemic inflammatory disorders in invasive bladder cancer. Curr Opin Urol 2011;21:428-433.

26 Kinoshita T, Ito H, Miki C: Serum interleukin-6 level reflects the tumor proliferative activity in patients with colorectal carcinoma. Cancer 1998;85:2526-2531.

27 McKeown DJ, Brown DJ, Kelly A, Wallace AM, McMillan DC: The relationship between circulating concentrations of C-reactive protein, inflammatory cytokines and cytokine receptors in patients with non-small-cell lung cancer. Br J Cancer 2004;91:1993-1995.

$28 \mathrm{Du}$ Clos TW, Mold C: C-reactive protein. An activator of innate immunity and a modulator of adaptive immunity. Immunol Res 2004;30: 261-277.

29 Canna K, McArdle PA, McMillan DC, et al The relationship between tumour T-lymphocyte infiltration, the systemic inflammatory response and survival in patients undergoing curative resection for colorectal cancer. Br J Cancer 2005;92:651-654.

30 Mancino A, Lawrence T: Nuclear factor-kap$\mathrm{paB}$ and tumour-associated macrophages. Clin Cancer Res 2010;6:784-789.

- 31 Hanahan D, Coussens LM: Accessories to the crime: functions of cells recruited to the tumour microenvironment. Cancer Cell 2012; 21:309-322.

32 Weis SM, Cheresh DA: Tumor angiogenesis: molecular pathways and therapeutic targets. Nat Med 2011;17:1359-1370.

- 33 McMillan DC, Scott HR, Watson WS, et al: Longitudinal study of body cell mass depletion and the inflammatory response in cancer patients. Nutr Cancer 1998;31:101-105. 